\section{Código de Ética del Colegio Médico de Chile. Análisis crítico de una modificación}

\author{
MAURICIO BESIO R., ${ }^{1,2}$
}

\section{Ethics code of the medical college of Chile. Critical analysis of a modification}

The code of ethics of the Medical College of Chile was modified in December 2019. The amendment was mainly to article 8, which refers to the doctor's duty to care for the pregnant woman and the child she is carrying. The change maintains this duty, but allows doctors to perform abortions, introducing three considerations that act as new principles or values for the medical profession: the plurality of values existing in society, the autonomy of women and what is established by law. This paper is a reflection on codes of ethics, their relationship with values, and with legislation. Also it shows the consequences that this modification represents for the principles governing medical activity, the status of medical specialties, the commitment of doctors to their patients and the validity of the code of ethics.

(Rev Med Chile 2020; 148: 399-403)

Key words: Bioethics; Codes of Ethics; Ethics.
'División de Obstetricia

y Ginecología. Pontificia

Universidad Católica de Chile.

Santiago, Chile.

${ }^{2}$ Departamento de Ética. Colegio

Médico de Chile.

Recibido el 17 de febrero de 2020, aceptado el 24 de abril de 2020.

Correspondencia a:

Dr. Mauricio Besio Rollero

Chile-España 1331. Santiago,

Chile.

besio@med.puc.cl
$\mathrm{E}$ n Diciembre del año 2019, el Consejo General del Colegio Médico de Chile aprobó el cambio del artículo $8^{\circ}$ del Código de Ética de esa institución ${ }^{1}$, artículo que ya había sido modificado el año 2004. El artículo original decía: "El respeto a la vida humana desde su inicio y hasta su término constituye un fundamento básico del ejercicio profesional médico. Toda intervención médica realizada durante los nueve meses de gestación, deberá velar siempre por el mejor interés de la mujer embarazada y del que está por nacer". El cambio aludido, consistió en agregar a esa redacción el párrafo siguiente: "Reconociendo la diversidad de valores existentes en la sociedad, en ciertas circunstancias la autonomía de la mujer embarazada es considerada por sobre el valor de la vida fetal, por lo que la legislación vigente permite la realización de una interrupción voluntaria del embarazo. En estos casos, el médico podrá practicarla, sin perjuicio de su derecho para excusarse de intervenir invocando la objeción de conciencia, en la forma que el ordenamiento jurídico y este Código determinen. Sin embargo, el ejercicio de esta facultad no lo exime de sus deberes de informar a la mujer embarazada sobre los derechos que la ley le confiere en esta materia ni de otorgarle los cuidados necesarios, anteriores y posteriores a la intervención".

Este cambio introduce una serie de problemas al estatuto de la profesión médica que nos obliga a una reflexión cuidadosa. El objetivo de este trabajo es mostrar cómo la modificación de un solo artículo del código de ética, conlleva un cambio profundo de los principios que rigen a nuestra actividad, al estatuto de las especialidades médicas, al compromiso de la profesión médica con sus pacientes y a la validez de nuestro código de ética.

La profesión médica no está ajena a los cambios, no está ajena a la discusión sobre miradas distintas sobre ella, y no está ajena tampoco a las distintas maneras de ver, juzgar y resolver los 
problemas que se les presentan a los pacientes y a nosotros los médicos. Algunos de los cambios se refieren a distintas o nuevas tecnologías, o a distintos escenarios donde ejercemos nuestra profesión y que requieren una reactualización constante de nuestro quehacer. Todos ellos los analizamos bajo la perspectiva de los principios y valores de nuestra actividad, buscando la manera de resolverlos desde el respeto a ellos. Pero existen otros cambios, que ya no se refieren a la forma como aplicamos esos principios, sino que buscan el cambio de esos principios y valores. Es este el tipo de cambio que aconteció con esta nueva versión del artículo $8^{\circ}$ y que provoca consecuencias serias respecto a nuestro quehacer, y complica la pertinencia de nuestro código de ética.

\section{Naturaleza y finalidad de los códigos de ética médica}

Un código de ética es un conjunto de normas que ciertos individuos, en este caso los médicos, deben respetar. De allí que se consideran códigos deontológicos (Deontología "ciencia o tratado de los deberes"). Los médicos deben en su desempeño profesional mantener una conducta que no vulnere las normas contenidas en ese cuerpo de reglas. Si nos fijamos en las características de esas reglas veremos que son de dos tipos; unas que se refieren a las acciones que los médicos deben realizar, y otras que no deben realizar. Vemos que se trata entonces de un conjunto de deberes y también de límites. Un médico tendrá toda la libertad para ejercer su actividad de la manera que estime conveniente, pero debe buscar siempre realizar cierto tipo de acciones y no debe traspasar ciertos límites en su actuar.

La importancia y la razón de la vigencia que tienen los códigos de ética médica, están relacionadas entonces primero con un aspecto disciplinario. Como fijan claramente la conducta que los médicos deben respetar, permite que los tribunales correspondientes puedan establecer justicia si alguien considera que algún profesional se desvió de lo que le correspondía hacer.

Sin embargo, estos códigos de ética tienen una segunda finalidad, quizás de mayor relevancia. Toda actividad humana se realiza con esfuerzo y dificultad, hasta que gracias a ese esfuerzo, poco a poco se va adquiriendo la facilidad para realizarla.
Lo que al inicio era arduo, una vez adquiridos los hábitos necesarios, se ejecuta con facilidad. Así como en la vida ciudadana las normas, leyes y costumbres tienen una función educativa, así también los códigos de ética, al ser códigos de conducta, sirven de guía para los que se inician en la actividad médica, o para aquellos que aun no han incorporado a modo de hábito aquella manera adecuada del actuar médico. También y en esa misma línea, sirven de consulta a aquellos médicos que dudan en una situación compleja, acerca de los cursos de acción conformes a la ética profesional. Es por ello la necesidad de que los códigos y sus artículos sean capaces de esclarecer, iluminar y servir de ayuda al juicio de conciencia del médico y no apelar a ese juicio sin esclarecerlo e iluminarlo.

Si nos fijamos en todos los juramentos, oraciones y códigos que buscan fijar la conducta de los médicos, nos damos cuenta que sus recomendaciones, aspiraciones o normas de un adecuado comportamiento, no surgen arbitrariamente ni tampoco por petición de los distintos individuos o grupos sociales. Las normas de los códigos de ética, se fundan en primer lugar en lo que la actividad médica es, es decir en su objeto. En segundo lugar en valores que surgen necesariamente de ese objeto.

Cuando hablamos de medicina, espontáneamente sabemos que nos referimos al cuidado de los enfermos. Siempre se ha entendido al médico como el poseedor de un cuerpo de conocimientos, teórico y práctico, que puede ser usado para tratar al enfermo ${ }^{2}$. El objeto de la medicina es entonces la salud de los pacientes, y a nosotros nos corresponde intentar restablecerla en un individuo que la ha perdido, o no la ha poseído nunca. Eso es todo. Si bien es cierto que consideramos en nuestro quehacer otros bienes que los pacientes pueden anhelar, no nos corresponde primariamente su satisfacción. Este objeto de la medicina establece por un lado esta obligación primaria e irrenunciable y por otro los límites de nuestro actuar $^{3}$. No podemos renunciar a la prevención de la enfermedad y al mantenimiento de la salud, al alivio del dolor y del sufrimiento, a la asistencia y curación de los enfermos y al cuidado de los que no pueden ser curados, ni a evitar la muerte prematura y velar por una muerte en $\mathrm{paz}^{4}$. De la misma manera, sí podemos negarnos a acciones que buscan otras aspiraciones de los pacientes, 
especialmente cuando vulneran nuestra principal responsabilidad.

Desde ese objeto, que establece nuestra responsabilidad y los límites de nuestra actividad, surgen otros valores, que actúan como principios de acción u omisión. Por ejemplo, honradez, respeto, confidencialidad, competencia etc.

Un código de ética debe entonces ser un cuerpo normativo que cumpla las condiciones de validez, solidez y persuasividad ${ }^{5}$. Se entiende por validez que sea un cuerpo coherente en sí mismo y que todos sus artículos sean concordantes entre sí. A la vez debe poseer solidez, es decir que sus enunciados sean verdaderos, fundados en lo que las cosas son, y en valores. Aquí el centro no está en la coherencia lógica sino que en las premisas (las razones) y en las conclusiones. Por último, y muy relacionado con las anteriores condiciones, un código de ética debe ser capaz de comunicar y persuadir. Debe ser capaz de mostrar a los colegiados, la belleza y bondad de sus postulados. De allí su relación con la validez y solidez.

\section{Código y legislación}

El cambio realizado por la directiva del Colegio Médico referido a las interrupciones del embarazo, corresponde a un cambio de principios o valores de la medicina. No corresponde a otros que se refieren a actualizaciones de la práctica médica.

Se pudiera llegar a pensar sin embargo, que es un cambio necesario para una adaptación a una nueva legislación, y es por ello que es necesario reflexionar con cuidado estos dos elementos: la necesidad o no de cambiar nuestro código frente a cambios legales o dejarlo suficientemente abierto a eventuales futuros cambios y en segundo lugar el tema de los valores o principios involucrados en nuestro código.

El primer tema corresponde a responder la pregunta ¿será necesario y conveniente que nuestro código de ética sea siempre concordante o suficientemente flexible con la legislación actual o futura? En una primera mirada se puede pensar que sí es conveniente. De hecho nos evitamos el gran problema que ciertas acciones de los médicos puedan ser permitidas o prohibidas por el código sin serlo por la legislación ${ }^{6}$. La concordancia facilita la acción de los tribunales de ética, ya que una sanción ética no sería contraria a la ley. Sin embargo, por alguna razón tenemos en nuestro código vigente artículos que no son concordantes con la legislación y que consideramos sumamente valiosos, y difícilmente los intentaríamos cambiar (ejemplo de ellos son el art. 31 que garantiza el secreto profesional incluso hasta después de la muerte del paciente, en clara contraposición con la Ley de Deberes y Derechos de los pacientes que permite el acceso a la ficha del fallecido por parte de sus herederos, o el art. 37 que impide cumplir lo acordado en contratos con los institutos de salud previsional, respecto a la entrega de información y todos los artículos relacionados con la publicidad).

Además si eso fuese así, debiéramos cambiar nuestro código de ética cada vez que hubiera un cambio legal, o dejarlo suficientemente laxo o elástico, compatible con cualquier legislación futura, lo que haría innecesaria su existencia. Bastaría solo con que la actividad médica se rigiera por la legislación; sin embargo la sociedad no lo considera así; ${ }^{7}$ de hecho, la Constitución establece la tutela ética por parte de los colegios profesionales, y estos con sus respectivos códigos de conducta ${ }^{8}$.

Como se dijo anteriormente, los códigos, juramentos y oraciones establecen deberes para los médicos desde que la medicina se constituyó como profesión, independiente de otras actividades como la religión o la filosofía". Lo "profesado", lo "declarado" por los médicos ha sido siempre independiente de las leyes. Ha sido una forma de actuar (ethos) siempre concordante con el objeto de la profesión (salud) y con los principios y valores derivados de ese objeto. Son innumerables los ejemplos a través de la historia en que esos postulados se enfrentan a las leyes imperantes (recuerden el trato a prisioneros, huelga de hambre, experimentación con sujetos humanos, confidencialidad frente a peticiones judiciales etc.).

Es evidente que el cambio propuesto al artículo relacionado con el aborto, se relaciona claramente con el cambio de la legislación chilena respecto a las "interrupciones del embarazo en tres causales" ${ }^{\prime \prime}$, y con él se pretende evitar que médicos que realicen abortos en esas tres causales sean juzgados y sancionados por nuestros tribunales de ética. De nuevo: ¿debiésemos cambiar los valores de nuestra profesión cada vez que alguna mayoría determine un cambio en las leyes? ¿deberíamos redactarlo de alguna manera para que no contradiga nunca a la ley?

Esto nos lleva al segundo tema planteado; el de 
los valores. Nuestro código de ética, con su última versión del año 2004 se sustenta en los valores y principios de la profesión médica, entre ellos “a los Deberes Generales del Médico, haciendo especial hincapié en el deber de respetar la vida humana desde su inicio y hasta su término" ${ }^{\prime 1}$.

\section{Código y valores}

El cambio realizado mantiene explícitamente el valor del respeto a la vida. Sin embargo, introduce otros tres condicionantes que actuarían como valores y que lo anulan completamente. ¿Qué sentido tiene explicitar el debido respeto a la vida desde su inicio y velar por los intereses de la mujer y del hijo que gesta, si su efectividad deja de ser cautelada por el código de ética médica, que fija lo que un médico puede o no puede hacer? El cambio introduce la autonomía de la mujer, la pluralidad social y lo permitido por la ley presente o futura, como otros valores, dándole la misma jerarquía. En otras palabras ha terminado siendo un valor en el que su respeto estará siempre dependiente de la ley y de la voluntad de la mujer.

Además, ¿es razonable que nuestro Código de Ética permita causar directamente la muerte de un paciente? Estando además claramente prohibido en el artículo 9o, ¿es razonable que lo permita sin intentar aliviar el sufrimiento, dolor y riesgo vital a todos y cada uno de los implicados? No parece posible que se le quite a una especialidad médica -Obstetricia- y a una subespecialidad -Medicina Materno Fetal- ambas reconocidas por nuestra orden, la obligación de cuidado a sus pacientes, compartida por todas las especialidades médicas ${ }^{12}$.

Si nuestra orden reconoce a la Obstetricia y a la Medicina Materno Fetal como especialidad y subespecialidad médica, un mínimo de coherencia exige que ambas disciplinas tengan las mismas exigencias éticas que todas las ramas de la Medicina. Estoy consciente que en varios países los códigos de ética, de manera más o menos laxa, permiten adaptaciones de forma tal que consideran al aborto como permisible. Sin embargo, mi oposición a cambiar el principio médico de protección a la vida de los pacientes, apela a la libertad de pensamiento y a la independencia de nuestros dirigentes, para juzgar mediante el libre uso de la razón sobre la gravedad de anular y dejar sin efecto un valor inmanente de la profesión médica.
Respecto al respeto de la autonomía, éste no es absoluto en nuestro código. Nos pone un límite en el actuar: no podemos imponer una intervención, así como no estamos obligados a actuar solo a petición de los pacientes. Si fuera así estaríamos obligados a violar muchos otros valores de la Medicina, otorgando licencias médicas, realizando intervenciones quirúrgicas, solicitando exámenes, sólo al recibir esas solicitudes. No tendría entonces ningún sentido la reflexión ética ni tampoco un código.

Además, la modificación en estos términos del artículo $8^{\circ}$ no consideró la trascendencia que tiene para otros temas, que nuestro código sí prohíbe a los médicos. Si analizamos algunos de ellos con el mismo prisma ¿cómo justificamos la prohibición de recibir aportes de la industria, si existen distintos valores en nuestros colegiados, si ellos tienen autonomía y la ley lo permite? ¿cómo podríamos limitar la publicidad de los médicos si sucede lo mismo? ¿cómo podría prohibir el colegio médico, por ejemplo, la participación de los colegas en peleas de box, si también concurren esos elementos?

\section{En resumen}

Este cambio no es meramente de actualización a una nueva situación vivida por pacientes y médicos. Es un cambio a uno de los valores más antiguos de la profesión médica y que actúa como principio fundante de muchos deberes y límites de nuestro actuar profesional.

El impacto que tendrá este cambio a un solo artículo del código puede ser analizado en tres niveles:

En una perspectiva práctica, los tribunales de ética de nuestra organización gremial -que aspira a tener la tutela del actuar de todos los médicos- tendrán serias dificultades para administrar justicia. Cuando se establecen, aunque sea en un solo artículo, condicionantes -que contrarían a un principio de la profesión como la prohibición de matar a un paciente-de carácter contingente y relativas, tales como apelaciones a leyes presentes o futuras, autonomía de las personas o la "diversidad de valores", no se puede impedir entonces que se apele a esos mismos valores contingentes y relativos, a otros artículos que protegen también principios de la profesión médica. Si ésta considera como valores no realizar publicidad, mantener la 
confidencialidad o una prescindencia de recibir regalos de la industria farmacéutica, no podrá amonestar a colegas que frente a una vulneración de esos valores apele a esos mismos principios tan variables.

En un segundo nivel, este único cambio determina incoherencias profundas no sólo en el mismo artículo modificado, sino que específicamente con el artículo $9^{\circ}$ que impide que un médico le quite directamente la vida a un paciente, dejando en una situación de menosprecio a especialidades médicas que se constituyen como tales considerando al feto como objeto de sus cuidados.

Es perfectamente lícito que los médicos puedan incorporar otros valores en su quehacer profesional, sin embargo ellos deben confrontar su jerarquía con los principios ya existentes. De ser contrarios y de menor valía, no se deben introducir. Esta carencia de solidez y validez ahora establecida, deja en entredicho la pertinencia de esta nueva versión del código y la legítima aspiración del Colegio Médico de Chile para recuperar la tutela ética de todos los médicos.

Por último, y de una especial trascendencia, si es nuestra obligación mostrar y encantar con su profesión a las nuevas generaciones de médicos: ¿Cómo lo vamos a hacer, si les presentamos un código de ética falto de solidez y con tantas incoherencias? ¿Cómo vamos a persuadirlos y encantarlos con un código de ética que por un lado intenta impedir que un médico reciba regalos de empresas farmacéuticas, o que publicite sus propios méritos clínicos o académicos, pero que a la vez le permite quitar la vida a un paciente vulnerable?

\section{Referencias}

1. Colegio médico de Chile. Disponible en: www.colegiomedico.cl/wp-content/uploads/2019/12/codigo-de-etica-final.PDF (Consultado el 11 de febrero de 2020).

2. Laín Entralgo P. Historia universal de la medicina. Barcelona: Salvat Editores; 1982. p. 74.

3. Besio M, Serani A, Sabiduría, naturaleza y enfermedad, una comprensión filosófica de las carreras de la salud. Santiago, Chile: Ediciones UC; 2014. p. 65-71.

4. The Hastings Center. The Hastings Center Report, 1996: nov-dic.

5. Atienza M. Curso de argumentación jurídica. Madrid: Editorial Trotta; 2013. p. 107-169.

6. Patuzzo S, De Stefano F, Ciliberti R. The Italian Code of Medical Deontology. Historical, ethical and legal issues. Acta Biomed 2017; (89,2): 157-164.

7. Cortina A. Universalizar la aristocracia: por una ética de las profesiones. Revista de Santander 2006; (1): 54-65.

8. Congreso Nacional de Chile. Constitución Política de la República de Chile Disponible en https://www.leychile. $\mathrm{cl} /$ Navegar?idNorma=242302. [Consultado 11 de febrero de 2020], art.19.

9. Zubiri X. Cinco lecciones de Filosofía. Madrid: Alianza Editorial; 1992 p. 19.

10. Congreso Nacional de Chile. Disponible en:https:// www.leychile.cl/Navegar?idNorma=1108237\&idparte=-ley21030... [Consultado 11 de febrero de 2020].

11. Colegio médico de Chile. Disponible en: www.colegiomedico.cl/wp-content/uploads/2019/12/codigo-de-etica-final.PDF[Consultado el 11 de febrero de 2020], p 20.

12. Besio M. Editorial; Aspectos bioéticos del aborto en Chile. Rev Chil Obstet Ginecol 2013; 78 (4): 257-8. 